\title{
DILEMA PROGRAM MDGS DALAM PENURUNAN ANGKA KEMATIAN IBU (AKI) DAN ANGKA KEMATIAN BAYI (AKB) MELALUI JAMPERSAL DI KABUPATEN TUBAN
}

\section{Dilemma Program MDGs In Maternal Mortality (MMR) And Infant Mortality (IMR) Reduction Through Jampersal In The District Tuban}

\author{
M. Amir. HT \\ Badan Penelitian dan Pengembangan Provinsi Jawa Timur \\ Jalan Gayung Kebonsari No. 56 Surabaya \\ E-mail: amirlitbang@yahoo.co.id \\ Dikirim: 23 Januari 2014; direvisi: 29 Januari 2014; disetujui: 12 Februari 2014
}

\begin{abstract}
Abstrak
Kajian ini merupakan implementasi program Jampersal yang dirancang dengan menggunakan pendekatan mixing methods yakni suatu kajian kualitatif, dipandu dengan angka-angka kuantitatif, untuk mengkaji secara mendalam suatu fenomena yang ada di masyarakat dengan tidak memanipulasi variabel-variabel (expost facto), menyangkut peristiwa yang sudah terjadi, berhubungan dengan kondisi sekarang terhadap pengguna Jampersal yang beralih pelaksanaannya ke JKN yang dikelola oleh BPJS sejak awal tahun 2014 . Tujuannya untuk mengetahui pelaksanaan program Jampersal, apakah program ini mencapai target dengan dana yang ada, sesuai harapan Millennium Development Goals (MDGs), dalam menurunkan AKI dan AKB di Kabupaten Tuban, yang akan berakhir pada tahun 2015 mendatang.

Kata kunci: Jampersal, menurunkan AKI dan AKB, program MDGs
\end{abstract}

\begin{abstract}
This study is an implementation program designed Jampersal Mixing Methods approach which is a qualitative study, guided by quantitative figures, to examine in depth a phenomenon that exists in society by not manipulate variables (ex post facto), concerning the events that have been occurred, associated with the present condition of the Jampersal users who switch to JKN implementation managed by BPJS since the beginning of 2014. The goal is to examine the implementation Jampersal program, whether the program is to reach the target with existing funds, as expected Millennium Development Goals (MDGs), in reducing the MMR and IMR in the district Tuban, which will expire in 2015.

Keywords: Jampersal, reducing the MMR and IMR, MDGs
\end{abstract}

\section{PENDAHULUAN}

Jaminan persalinan (Jampersal) adalah jaminan pembiayaan yang digunakan untuk meningkatkan akses masyarakat terhadap pelayanan kesehatan kehamilan, pertolongan persalinan, pelayanan kesehatan nifas termasuk KB pascapersalinan dan pelayanan bayi baru lahir. Sejak diluncurkan 2011, Jampersal telah dilaksanakan oleh kabupaten/kota di seluruh tanah air dan telah dirasakan manfaatnya oleh masyarakat.

Namun demikian sebagai program yang masih relatif baru, pelaksanaan Jampersal tidak lepas dari berbagai kekurangan yang perlu dibenahi. Hal tersebut diketahui antara lain dari berbagai hasil penelitian yang dilakukan beberapa pihak. Salah satu penelitian adalah Studi Evaluatif Implementasi Jaminan Persalinan Tahun 2012 yang dilakukan oleh Badan Penelitian dan Pengembangan Kesehatan Kementerian Kesehatan, tepatnya oleh Pusat Humaniora.

Secara umum, studi evaluatif tersebut bertujuan untuk mengetahui implementasi program Jampersal terhitung sejak peluncuran 2011 hingga pertengahan 2012. Secara khusus, studi evaluatif ini bertujuan untuk mengetahui akseptabilitas kebijakan Jampersal di tingkat operasional, kapasitas manajerial penyelenggara program dan penyedia layanan, ketepatan program dan sasaran, serta faktor kontekstual terkait dengan tingkat pencapaian program Jampersal.

Kemudian kalau kita simak pembangunan kesehatan saat ini, telah berhasil meningkatkan status kesehatan masyarakat. Sejak periode 2004 sampai dengan 2007 terjadi penurunan Angka Kematian Ibu (AKI) dari 307 per 100.000 kelahiran hidup menjadi 228 per 100.000 kelahiran hidup dan Angka Kematian Bayi (AKB) dari 35 per 1.000 kelahiran hidup menjadi 34 per 1.000 kelahiran hidup. Namun demikian keberhasilan tersebut masih perlu terus ditingkatkan, mengingat AKI dan AKB di Indonesia masih cukup tinggi dibandingkan dengan negara ASEAN lainnya.

Target RPJMN Tahun 2010-2014 mengamanatkan agar AKI dapat diturunkan menjadi 118 per 100.000 kelahiran hidup pada tahun 2014 . Selain itu, kesepakatan global Millennium Development Goals (MDGs) menargetkan AKI di Indonesia dapat diturunkan menjadi 102 per 100.000 kelahiran hidup pada tahun 2015 nanti. Upaya penurunan AKI harus difokuskan pada penyebab 
langsung kematian ibu, yang terjadi $90 \%$ pada saat persalinan dan setelah pesalinan, yaitu perdarahan (28\%), eklamsia (24\%), infeksi (11\%), komplikasi pueperium $8 \%$, partus macet $5 \%$, abortus $5 \%$, trauma obstetrik 5\%, emboli 3\%, dan lain-lain 11\% (sumber diskes prov. jatim).

Kematian ibu juga masih banyak diakibatkan faktor resiko tidak langsung berupa keterlambatan. Ada tiga (terlambat), yaitu: 1) terlambat mengambil keputusan dan mengenali tanda bahaya; 2) terlambat dirujuk; dan 3) terlambat mendapat penanganan medis. Salah satu upaya pencegahannya adalah melakukan persalinan yang ditolong oleh tenaga kesehatan difasilitasi pelayanan kesehatan.

Jampersal dimaksudkan untuk menghilangkan hambatan finansial bagi ibu hamil untuk mendapatkan jaminan persalinan, yang di dalamnya termasuk pemeriksaan kehamilan, pelayanan nifas termasuk $\mathrm{KB}$ pascapersalinan, dan pelayanan bayi baru lahir. Dengan demikian, kehadiran Jampersal diharapkan dapat mengurangi terjadinya tiga terlambat tersebut sehingga dapat mengakselerasi tujuan pencapaian MDGs, khususnya MDGs 4 dan 5.

Terdapat beberapa pembenahan pada skema Jampersal 2012, di antaranya:

1. Perluasan pelayanan kesehatan yang dijamin;

2. Peningkatan besaran tarif pelayanan yang ditanggung;

3. Pembenahan pada pengorganisasian di tingkat pusat, provinsi, dan kabupaten/kota; dan

4. Mekanisme pengelolaan keuangan/dana baik di tingkat dasar maupun tingkat lanjutan.

Hal yang tidak boleh dilupakan adalah bahwa Jampersal merupakan paket pelayanan termasuk di dalamnya pelayanan KB pascapersalinan. Sehingga setiap pasien penerima manfaat Jampersal, setelah melahirkan harus mengikuti program $\mathrm{KB}$ pascapersalinan. Dengan demikian, program Jampersal ini akan sejalan dengan program KB.

Kenaikan biaya program Jampersal ini disambut positif Dinas Kesehatan Jatim. Kenaikan klaim Jampersal ini diharapkan dapat menarik Bidan Praktik Swasta (BPS) untuk ikut serta menyukseskan program ini. pada awal program Jampersal ini diluncurkan Kementrian Kesehatan banyak bidan yang belum tertarik, mengingat klaimnya yang hanya Rp 420.000,00. Padahal biasanya setiap layanan persalinan biayanya sebesar Rp 600.000,00. Karena itu, tidak bisa memaksa bidan untuk ikut serta dalam program Jampersal ini, namun Diskes Jatim tetap menganjurkan agar mereka ikut karena tujuan dari program ini sangat bagus. Jampersal sendiri merupakan program pemeriksaan kehamilan (antenatal), persalinan, dan pemeriksaan bagi seluruh ibu hamil yang menggunakan fasilitas kesehatan yang bekerja sama dengan program pembiayaannya ditanggung pemerintah. Meskipun tidak masuk dalam Jamkesmas, yang saat ini beralih ke BPJS, tetap dilayani.
Pelaksanaannya, Jampersal menetapkan sistem klaim (reimbursement). Proses klaim bagi Puskesmas, klinik, rumah bersalin swasta dan Polindes memberikan pelayanan terlebih dahulu, apabila sudah memberikan pelayanan persalinan, maka klinik, rumah bersalin swasta atau Polindes tersebut bisa mengajukan klaim ke tempat pelayanan Jamkesmas saat ini oleh BPJS di Diskes Kabupaten/Kota dengan melengkapi bukti-bukti pelayanan.

Sementara untuk klinik, rumah bersalin swasta tersebut harus sudah mengadakan MoU dengan Dinas Kesehatan setempat, kecuali untuk Puskesmas, Polindes dan bidan kelurahan/desa, secara otomatis harus menerima pasien dengan Jampersal tanpa perlu MoU terlebih dahulu. Dengan demikian perlunya mengkaji penyelenggaraan program Jampersal di Kabupaten Tuban di Jawa Timur, yang beralih pelaksanaannya ke JKN yang dikelola oleh Badan Penyelenggara Jaminan Sosial (BPJS), program kesehatan akan mulai menerapkan jaminan kesehatan pada 1 Januari 2014, berdasarkan Peraturan Presiden Nomor 12 Tahun 2013 tentang Jaminan Kesehatan, penerima bantuan iuran jaminan kesehatan itu adalah fakir miskin dan orang tidak mampu.

Jaminan kesehatan adalah jaminan berupa perlindungan kesehatan agar peserta memperoleh manfaat pemeliharaan kesehatan, dan perlindungan dalam memenuhi kebutuhan dasar kesehatan yang diberikan kepada setiap orang yang telah membayar iuran atau iurannya dibayar oleh pemerintah. Sementara itu, Badan Penyelenggara Jaminan Sosial Kesehatan yang selanjutnya disingkat BPJS Kesehatan adalah badan hukum yang dibentuk untuk menyelenggarakan program jaminan kesehatan tersebut.

Menteri Koordinator Kesejahteraan Rakyat, Agung Laksono, mengatakan, masyarakat berpenghasilan rendah nantinya cukup membayar premi Rp 15.500 per bulan untuk menikmati manfaat dari BPJS Kesehatan itu. Sementara, sisanya dibayarkan pemerintah melalui Anggaran Pendapatan dan Belanja Negara (APBN). Meski besaran premi itu lebih kecil dari usulan sebelumnya Rp 22.200 per bulan, ketentuan tersebut akan diperkuat dengan peraturan menteri atau peraturan pemerintah. Menurut menteri, saat ini, pemerintah tengah menyiapkan infrastruktur terkait, seperti perbaikan Puskesmas, rumah sakit, dan keperluan penunjang lainnya. kemudian, Menteri Keuangan, Agus Martowardojo, mengatakan, besaran premi yang ditetapkan tersebut tidak akan membebani Anggaran Pendapatan dan Belanja Negara. Menurutnya, semua itu sesuai dengan kapasitas fiskal kita (Jakarta, Rabu 27 Februari 2013).

Menurut Agus Martowardojo, BPJS Kesehatan tersebut akan menjamin 86 juta penduduk yang masuk kategori miskin, dan berpenghasilan rendah. Jumlah itu juga disepakati dalam rapat koordinasi yang dilakukan kementerian-kementerian terkait. "Kementerian Kesehatan juga harus mempersiapkan fasilitas, mulai dari perawatan kesehatan, Puskesmas 
sampai rumah sakit, juga kesiapan dari para pekerjanya," ujarnya. Ditegaskan, pemerintah sangat serius dalam mewujudkan jaminan kesehatan ini. Sebab, nantinya, peningkatan jaminan sosial bagi masyarakat diharapkan dapat berjalan dengan baik. Agus menambahkan, "Ini adalah program yang akan dicanangkan pada 2014, dan ini akan berlanjut sampai 2019. Basis datanya berdasarkan APBN." Sementara program MDGs menurunkan AKI dan AKB berakhir pada tahun 2015 .

\section{METODE PENELITIAN}

Desain kajian ini adalah kualitatif dengan teknik pengambilan data secara triangulasi melalui informan, metode pengumpulan data dan cara analisis data untuk mengetahui peningkatan pencapaian target pelaksanaan program Jampersal. Kajian ini merupakan implementasi program Jampersal yang dirancang dengan menggunakan pendekatan Mixing Methods (gabungan metode penelitian) yakni suatu kajian kualitatif, yang ingin mengkaji secara mendalam suatu fenomena yang ada di masyarakat menyangkut peristiwa yang sudah terjadi, berhubungan dengan kondisi sekarang.

Secara kualitatif kajian ini akan menggali data dinamis sedalam mungkin dengan jalan melakukan wawancara mendalam kepada setiap pengguna Jampersal dan aparat pelayanan Jampersal, yang merupakan data primer. Kemudian data sekunder yang akan dihimpung, dikumpulkan melalui dokumen yang ada pada obyek kajian, selanjutnya melalui regulator berupa cross check kebenarannya dengan melakukan klarifikasi dan validasi data dari wawancara, dengan demikian akan diketahui pelaksanaan program Jampersal mencapai target dengan dana yang ada.

\section{Lokasi dan Sampel}

Kajian ini dilaksanakan selama 6 bulan mulai dari 1 Juli 2013 sampai dengan Desember 2013, tempat kajian di Kabupaten Tuban dengan sampel 1 rumah sakit: 10 orang pengguna Jampersal, dan 2 Puskesmas masing-masing 10 pengguna Jampersal termasuk bidan yang melayani.

Populasi dari kajian ini adalah, 30 orang pengguna dan bidan sebagai pelayanan kesehatan dalam program Jampersal. Penentuan sampel dilakukan melalui teknik purposive sampling, dengan merajuk kepada data Diskes Kabupaten Tuban yang berorientasi terhadap pelayanan kesehatan baik di rumah sakit umum/swasta dan di Puskesmas dalam pelaksanaan program Jampersal.

\section{Teknik Pengumpulan dan Analisa Data}

Data dikumpulkan dengan menggunakan teknik sebagai berikut:

a. Angket, untuk menjaring data awal yang berupa data primer; b. Wawancara, mendalam (indepth interview) untuk memperdalam kebenaran data yang diperoleh melalui angket;

c. Dokumentasi, untuk mengecek kebenaran data melalui bukti dokumentatif;

d. Observasi, untuk melihat secara riil kondisi pelaksanaan program Jampersal dalam menurunkan AKI dan AKB (dilapangan diambil secara reprensentatif);

e. Discussion/wawancara, kepada pengguna Jampersal dan pelayanan bidan untuk memproleh data secara lebih mendalam terhadap pelaksanaan program Jampersal.

Untuk menjawab rumusan masalah dan menguji asumsi di atas, maka peneliti menggunakan rancangan analisis data dilakukan secara mendalam sehingga memunculkan solusi tindak lanjut yang tepat, maka seluruh data dianalisis, diarahkan untuk memperoleh gambaran tentang program penyelenggaraan Jampersal yang lokusnya di Kabupaten Tuban, sehingga teknik analisis yang digunakan dalam kajian ini adalah analisis wacana (discourcess analysis).

Secara garis besar analisis data dilaksanakan dengan tahapan sebagai berikut:

a. Mengelompokan data sesuai dengan permasalahan yang akan dijawab:

b. Menganalisis data melalui tahapan checking, editing dan tabulasi yang disesuaikan dengan jenis data. (tahapan ini dilakukan baik secara deskriptif kualitatif maupun bila dimungkinkan kuantitatif dengan teknik scoring);

c. Merumuskan draft awal temuan dan hasil kajian;

d. Presentasi rumusan draft awal temuan pada stakeholder tentang program Jampersal yang lokusnya di Kabupaten Tuban, untuk mendapatkan umpan balik yang dikemas dalam bentuk diskusi;

e. Rumusan draft akhir temuan dan hasil kajian, yang berdampak positif terhadap pembangunan kesehatan masyarakat, khusus capaian target penyelenggaraan Jampersal dalam menurunkan tingkat kematian ibu dan bayi lahir, dan peningkatan peserta KB.

\section{HASIL DAN PEMBAHASAN}

Dalam analisis kajian ini, mengambil sampel di Kabupaten Tuban, sebagai gambaran yang bisa digeneralisasi bila ada kesamaan karakteristik daerahnya.

\section{Pola pelaksanaan Jampersal di Kabupaten/Kota.}

Pola pelaksanaan pelayanan Jampersal, khusus pelayanan persalinan dilakukan secara terstruktur dan berjenjang berdasarkan rujukan, sebagai berikut:

a. Pelayanan persalinan tingkat I (dilakukan di Puskesmas, Pustu, Polindes, BPS); dan 
b. Pelayanan persalinan tingkat lanjutan (dilakukan di Rumah Sakit).

\section{Ketersediaan petugas layanan}

Ketersediaan petugas layanan seperti dokter, bidan dan bidan pembantu dalam pelayanan Jampersal, baik di rumah sakit, Puskesmas, maupun di Puskesmas pembantu dan di Polindes, dapat disimak pada tabel dibawah ini:

Tabel 1. Jumlah Petugas Layanan

\begin{tabular}{clccc}
\hline & & \multicolumn{3}{c}{ Jumlah } \\
\cline { 3 - 5 } No & Institusi & Dokter & Bidan & $\begin{array}{c}\text { Pemb. } \\
\text { Bidan }\end{array}$ \\
\hline 1 & RSUD & 4 & 29 & - \\
2 & Puskesmas & 37 & 85 & - \\
3 & Pustu & - & - & - \\
4 & Polindes & - & 295 & - \\
\hline \multicolumn{3}{l}{ Sumber: Kantor Dinas Kesehatan Kabupaten Tuban }
\end{tabular}

Dalam pelaksanaanya Jampersal yang ada di rumah sakit untuk obsgun 4/anak 1, sedangkan di Puskesmas, dan di Puskesmas pembantu 85 bidan secara terjadwal melayani di dua tempat Puskesmas dan Pustu.

Kendati program Jampersal, di Jawa Timur telah berjalan, namun sering kali anggarannya terlambat. Sesuai mekanisme, anggaran dari Kementerian Kesehatan (Kemenkes) akan dikirim ke rekening Dinas Kesehatan setempat. Untuk mendapatkan uang jaminan itu, ibu yang hamil paling tidak harus telah empat kali memeriksakan kandungan ke berbagai tempat layanan kesehatan, seperti Puskesmas, Posyandu maupun praktik dokter atau bidan. Hanya saja, khusus praktik dokter dan bidan harus sudah menjalin kerjasama operasional dengan Dinkes.

Setiap ibu hamil akan mendapatkan alokasi jaminan sebanyak Rp 500.000,00,- sesuai alur administrasi, klaim dilakukan oleh Puskesmas atau bidan dan dokter ke Diskes. Anggaran itu diperuntukkan bagi ibu hamil ketika periksa hingga masa nifas, termasuk jasa memandikan bayi dan sebagainya.

Jampersal merupakan program Kemenkes yang berasal dari belanja bantuan sosial APBN. Dasarnya adalah Peraturan Menteri Kesehatan Nomor 631/MENKES/PER/III/2011. Tujuan digulirkannya program tersebut adalah untuk mendorong percepatan pencapaian satu tujuan Millenium Development Goals (MDGs) 2015 mendatang, yakni menurunkan angka kematian anak dan meningkatkan kesehatan ibu. Program itu mencakup pemeriksaan kehamilan, pertolongan persalinan, pelayanan nifas, termasuk pelayanan KB pascapersalinan. Alokasi anggaran Jampersal akan disalurkan ke masing-masing Puskesmas. Besar kecilnya anggaran ditentukan banyaknya ibu hamil yang tercatat di lokasi pelayanan kesehatan itu. Namun jika di tengah perjalanan salah satu Puskesmas kekurangan anggaran, maka bisa diambilkan dari Puskesmas lain yang anggarannya belum terserap habis. Tetapi jika pada akhir tahun anggaran masih tersisa, harus dikembalikan ke Diskes.

\section{Kapasitas pelayanan Jampersal}

Jumlah rumah sakit, Puskesmas, Pustu dan Polindes yang melayanan persalinan untuk tahun 2011 sampai dengan 2013, dapat disimak pada tabel dibawah ini:

Tabel 2. Jumlah Sarana Pelayanan Jampersal

\begin{tabular}{clc}
\hline No & \multicolumn{1}{c}{ Institusi } & Jumlah \\
\hline 1 & RSD Dr. R. Koesma & 1 \\
2 & Puskesmas & 33 \\
3 & Pustu & 54 \\
4 & Polindes & 272 \\
\hline
\end{tabular}

Sumber: Ktr diskes Kab. Tuban

Jawa Timur adalah provinsi terbesar di Indonesia, dengan permasalahan kesehatan yang cukup kompleks dan bervariasi. Penduduk yang banyak hampir mencapai 38 juta jiwa lebih menjadikan penanganan kesehatan harus semakin intens terhadap pembangunan kesehatan. Namun demikian tidak semua kabupaten/kota mempunyai pembiayaan kesehatan yang cukup memadai untuk mengurangi permasalahan kesehatan di daerah utamanya operasional kegiatan di Puskesmas. Puskesmas sebagai ujung tombak pelayanan kesehatan seharusnya memperoleh kecukupan anggaran untuk pelayanan kepada masyarakat utamanya untuk promosi dan prevensi dalam rangka mencapai derajat kesehatan yang optimal. Menyadari hal tersebut pemerintah Pusat meluncurkan Program Bantuan Operasional Kesehatan (BOK) yang kemudian ditindaklanjuti melalui Peraturan Menteri Kesehatan RI Nomor 2556/MENKES/PER/XII/2011 tentang Petunjuk Teknis BOK.

Pola pelaksanaan pelayanan Jampersal di Kabupaten Tuban, khusus pelayanan persalinan dilakukan secara terstruktur dan berjenjang berdasarkan rujukan, pelayanan persalinan tingkat I (dilakukan di Puskesmas, Pustu, Polindes, BPS). Kemudian pelayanan persalinan tingkat lanjutan (dilakukan di rumah sakit). Sedangkan kondisi pelayanan kesehatan terkait Jampersal, menunjukkan bahwa ada, 28 bayi di Kabupaten Tuban meninggal sepanjang 2013. Angka kematian ibu melahirkan dan bayi di Kabupaten Tuban dalam lima tahun terakhir cenderung meningkat. Tiap tahun, setidaknya ada sepuluh ibu melahirkan dan 100 bayi yang meninggal karena berbagai persoalan. Berdasarkan data dari Dinas Kesehatan Tuban, pada tahun 2008 terdapat sepuluh ibu dan 161 bayi yang meninggal. Jumlah ini sempat mengalami penurunan pada 2009, yakni sebelas ibu dan 118 bayi yang meninggal, namun pada 2010 jumlahnya meningkat lagi menjadi sepuluh ibu dan 167 bayi yang meninggal. Jumlah meningkat lagi 
pada 2011 menjadi delapan belas ibu dan 174 bayi yang meninggal. Selanjutnya pada 2012 menjadi delepan belas ibu dan 155 bayi yang meninggal.

Kemudian pada tahun 2013, sampai dengan bulan Mei sudah ada lima ibu dan 28 bayi yang meninggal. Menurut Kepala Dinas Kesehatan Tuban dr. Syaiful Hadi, penyebab kematian terbanyak disebabkan karena faktor penyakit yang diderita ibu ataupun bayi. Penyakit itu meliputi, kanker, paru-paru, diabetes dan penyakit lainnya yang dapat membahayakan kesehatan ibu serta bayi. Selain faktor penyakit, faktor lain yang juga bisa menjadi penyebab ibu atau bayi meninggal adalah asupan gizi pada bayi yang kurang, infeksi, atau gangguan pernapasan. "Kebanyakan penyakit ini baru terdeteksi setelah mereka diperiksa, karena itu kami sarankan agar para ibu atau bayi diperiksa secara rutin. Apalagi saat ini ada Jampersal bagi masyarakat," kata Syaiful Hadi di kantornya. Syaiful menjelaskan progam Jampersal saat ini masih berjalan dengan baik, namun dalam prakteknya kesadaran masyarakat terkait kehamilan masih kurang. Misalnya saja, kesadaran untuk ibu yang mempunyai penyakit agar tak hamil lebih dulu karena membahayakan janin atau bayi.

Karena itu, kata Syaiful, hingga kini pihaknya terus mensosialisasikan progam ini pada seluruh masyarakat. Untuk diketahui, dengan progam Jampersal ini seluruh ibu hamil bisa memeriksakan diri ke Posyandu atau Puskesmas secara gratis. Syaratnya ibu hamil tersebut harus membawa kartu Jampersal saat pemeriksaan. Selain itu kegiatan Jampersal yang lain adalah berupa sosialisasi kesehatan pada masyarakat. (Kamis, 16 Mei 2013 14:53 WIB Net Ilustrasi Laporan Wartawan Surya, Adrianus Adhi TRIBUNJATIM.COM, Tuban).

\section{Jumlah Dana, Peserta, dan Sarana Pelayanan Jampersal \\ Untuk mengetahui jumlah dana dalam} penyelenggaraan Jampersal dapat di simak pada tabel di bawah ini dari tahun 2011, 2012, dan 2013:

Tabel 3. Jumlah Dana dalam Pelayanan Jampersal Tingkat I

\begin{tabular}{clc}
\hline No & \multicolumn{1}{c}{ Tahun } & Jumlah dana Rp. \\
\hline 1. & 2011 & Rp 1.722.193.000,00- \\
2. & 2012 & Rp 6.459.004.000,00- \\
3. & 2013 s/d bulan Juni & Rp 3.459.868.300,00- \\
\hline
\end{tabular}

Sumber: Kantor Dinas Kesehatan Kabupaten Tuban.

\section{Tujuan pembiayaan $\mathrm{BOK}$}

a. Menyediakan dukungan biaya upaya pelayanan kesehatan yang bersifat promotif dan preventif bagi masyarakat;

b. Meningkatkan kualitas manajemen Puskesmas terutama dalam perencanaan tingkat Puskesmas dan lokakarya mini Puskesmas; c. Meningkatkan upaya penggerakan potensi masyarakat dalam meningkatkan derajat kesehatannya; dan

d. Meningkatkan cakupan pelayanan kesehatan yang bersifat promotif dan preventif yang dilakukan oleh Puskesmas dan jaringannya serta Poskesdes dan Posyandu.

BOK juga dimaksudkan untuk mendorong Puskesmas agar mampu mengidentifikasi permasalahan di wilayahnya melalui mini lokakarya yang selanjutnya dapat disusun rencana tindak lanjut untuk pemecahan masalah tersebut.

Kebijakan operasional BOK utamanya adalah BOK merupakan bantuan pemerintah pusat kepada pemerintah daerah dalam melaksanakan SPM Bidang Kesehatan untuk pencapaian MDGs Bidang Kesehatan tahun 2015 melalui peningkatan kinerja Puskesmas dan jaringannya serta Poskesdes dan Posyandu dalam menyelenggarakan pelayanan kesehatan yang bersifat promotif dan preventif.

BOK dimulai pada tahun 2010 pada tahun 2011 dan 2012 ini BOK diluncur sebagai Dana Tugas Pembantuan di Kabupaten/Kota. Tahun 2012 Provinsi Jawa Timur mendapat BOK sebesar Rp 83.029.625.000,00- yang masing-masing kabupaten/ kota mempunyai alokasi yang berbeda. Alokasi anggaran tersebut kemudian dibagi lagi ke Puskesmas sesuai dengan usulan (POA) dari Puskesmas di masing-masing daerah. Anggaran tersebut digunakan untuk membiayai transportasi petugas kesehatan, kader, dukun untuk kegiatan kesehatan ibu dan anak termasuk KB; imunisasi; promosi kesehatan; kesehatan lingkungan; pengendalian penyakit dan perbaikan gizi seperti pemberian makanan tambahan (PMT) serta penyuluhan PMT.

Pemulihan, gizi buruk pascaperawatan dan ibu hamil dan pertemuan-pertemuan yang bertujuan untuk peningkatan peran serta masyarakat. Terdapat perubahan yang cukup bermakna pada BOK tahun 2012. Bila tahun sebelumnya BOK difokuskan pada enam upaya kesehatan promotif preventif meliputi KIA-KB, imunisasi, perbaikan gizi masyarakat, promosi kesehatan, kesehatan lingkungan dan pengendalian penyakit, maka pada tahun 2012 BOK lebih diperluas dengan adanya tambahan untuk satu upaya kesehatan lain yang sesuai dengan risiko dan masalah utama kesehatan di wilayah setempat dengan tetap mengacu pada pencapaian target Standar Pelayanan Minimal (SPM) serta target MDGs Bidang Kesehatan tahun 2015.

Pada tanggal 27 Desember 2011, Menteri Kesehatan telah menandatangani Peraturan Menteri Kesehatan Nomor 2562/Menkes/Per/XII/2011 tentang Petunjuk Teknis Jaminan Persalinan. Dengan demikian secara resmi Petunjuk Teknis Jaminan Persalinan (Juknis Jampersal) Tahun 2012 telah diterbitkan dan kegiatan Jampersal telah siap dilaksanakan per 1 Januari 2012.

Dengan dukungan Jampersal diharapkan makin mengurangi hambatan finansial (financial barrier) 
yang dihadapi masyarakat yang selama ini tidak memiliki jaminan pembiayaan persalinan, agar mereka dapat mengakses pelayanan kesehatan ibu yang berkualitas, dalam upaya percepatan penurunan angka kematian ibu di Indonesia.

\section{Responses to Juknis Jampersal 2012}

Kemudian kondisi pelayanan kesehatan terkait Jampersal, menunjukkan bahwa ada, 28 bayi di Tuban meninggal sepanjang 2013. Angka kematian ibu melahirkan dan bayi di Kabupaten Tuban dalam lima tahun terakhir cenderung meningkat. Tiap tahun, setidaknya ada sepuluh ibu melahirkan dan 100 bayi yang meninggal karena berbagai persoalan.

Progam Jampersal saat ini masih berjalan dengan baik, namun dalam praktiknya kesadaran masyarakat terkait kehamilan masih kurang. Misalnya saja, kesadaran untuk ibu yang mempunyai penyakit agar tak hamil lebih dulu karena membahayakan janin atau bayi, hingga kini pihaknya terus mensosialisasikan progam ini pada seluruh masyarakat. Untuk diketahui, dengan progam Jampersal ini seluruh ibu hamil bisa memeriksakan diri ke Posyandu atau Puskesmas secara gratis. Syaratnya ibu hamil tersebut harus membawa kartu Jampersal saat pemeriksaan, untuk diganti kartu BPJS.

Pelaksanaan program jaminan persalinan gratis di Jawa Timur dianggap belum maksimal. Hal ini lantaran rendahnya respon yang diberikan oleh rumah sakit dan para bidan swasta. "Kedua hal itu sepertinya menjadi penyebab utama," ucap Kepala Dinas Kesehatan Jawa Timur, Mudjib Affan. Kendati demikian, ia mengaku tidak bisa memberikan paksaan kepada pihak rumah sakit dan bidan untuk menerapkan program Jampersal. Penyebab lain, kata Mudjib, yakni karena rendahnya anggaran yang telah ditentukan oleh Kementerian Kesehatan, yakni hanya Rp 420.000,00. Padahal, biaya normal yang harus dikeluarkan untuk melakukan persalinan dengan jasa bidan mencapai Rp 600.000,00. Kemungkinan, kata Mudjib, penolakan yang dilakukan bidan dan rumah sakit dikarenakan kecilnya biaya kompensasi yang diberikan. Kendati demikian, ia tetap meminta kepada masyarakat agar tidak patah arang. Pasalnya, program tersebut tetap berjalan di sejumlah instansi, seperti Puskesmas, bidan desa, dan Polindes.

Sedangkan jumlah peserta pengguna Jampersal dapat dilihat pada tabel dibawah ini, dari tahun 2011, 2012, dan 2013 sebagai berikut:

Tabel 4. Jumlah Peserta Pengguna Jampersal

\begin{tabular}{ccc}
\hline No & Tahun & Jumlah Peserta Pengguna \\
\hline 1 & 2011 & 4.415 orang \\
2 & 2012 & 11.884 orang \\
3 & 2013 & 5.579 orang \\
\hline
\end{tabular}

Sumber: Kantor Dinas Kesehatan Kabupaten Tuban.
Sarana/prasarana yang menunjang pelaksanaan kelancaran pelayanan program Jampersal selama ini, sebagai berikut:

- Pelayanan di Puskesmas. Puskesmas Pembantu, Polindes disediakan oleh Puskesmas, tetapi kadang-kadang ada kekurangan;

- Pelayanan oleh BPM disediakan sendiri oleh Balai Pengobatan Masyarakat.

Kemudian kendala dan hambatan dalam pelayanan program Jampersal yaitu:

- Pada awal adanya program Jampersal ada sebagian pasien yang menolak, tetapi lamakelamaan dengan adanya sosialisasi dari petugas, pasien sudah terbiasa/mengerti;

- Tahun 2011 ada gejolak dari petugas pelayanan (bidan) dengan adanya tarif persalinan yang terlalu rendah $\mathrm{Rp} 350.000,00$ - (tiga ratus lima puluh ribu rupiah), tetapi pada tahun 2012 sudah ada kenaikan sebesar Rp 500.000,00- (lima ratus ribu rupiah), tetapi dengan perkembangan teknologi ilmu kebidanan sekarang di Kabupaten Tuban untuk menekan Angka Kematian Ibu (AKI), Angka Kematian Bayi (AKB), persalinan harus ditolong dua orang bidan (dalam hal pelayanan persalinan di Kabupaten Tuban tidak ada masalah), tetapi perlu dipertimbangkan ada kenaikan tarif persalinan dari Rp 500.000,00untuk tahun berikutnya.

Meski sejauh ini ini petunjuk teknis pelaksanaan program Jampersal gratis belum turun tapi bagi penduduk yang belum memiliki jaminan kesehatan sudah bisa melakukan. Bahkan pembiayaan gratis ini tidak hanya berlaku untuk pertolongan pada persalinan normal tapi juga bagi persalinan melalui caesar.

\section{Kebijakan}

Implementasi peraturan menteri kesehatan nomor 2562/MENKES/PER/XII/2011 terkait pelaksanaan jaminan persalinan pada fasilitas kesehatan tingkat pertama melalui bidan praktik mandiri. Permasalahan dalam pelaksanaan jaminan persalinan pada fasilitas kesehatan tingkat pertama melalui bidan praktik mandiri (BPM), terjadi sebab banyak bidan yang memilih untuk tidak melaksanakan peraturan menteri kesehatan tersebut dengan konsisten. Karena biaya klaim yang dirasa kurang dan syarat administrasi pengajuan klaim yang dianggap berbelit-belit, hal tersebut disebabkan kebanyakan dari bidan jarang melakukan pencatatan pemeriksaan sesuai dengan standar KIA/KB dan standar kesehatan masyarakat.

Adapun hambatan dari implementasi program jaminan persalinan yakni belum ada dukungan kongkrit, hal ini ditunjukan dengan belum adanya turunan kebijakan yang dibuat sebagian oleh pemerintah kabupaten/kota untuk memperkuat implementasi Jampersal di lapangan, misalnya dengan menetapkan peraturan bupati/walikota untuk menyelaraskan besaran tarif dengan peraturan daerah, 
membuat petunjuk teknis turunan, serta mendorong Jampersal, kurang aktifnya partisipasi BPM dalam melaksanakan program pemerintah ini.

Hal tersebut diakibatkan karena penyebaran informasi mengenai program ini yang tidak merata. Upaya yang dilakukan dalam mengatasi hambatan tersebut antara lain sudah sepatutnya pemerintah Kabupaten/Kota mengeluarkan aturan turunannya seperti Perbup/Perwali atau Perda kabupaten/kota untuk menjamin pelaksanaan Jampersal itu sendiri. Dinas Kesehatan mengedukasi dan memberikan arahan kepada para BPM terkait, pelaksanaan Jampersal, meningkatkan pengawasan dan pembinaan kepada BPM yang melakukan pelayanan Jampersal sehingga pelaksanaan Jampersal dapat terlaksana berdasarkan perjanjian kerjasama dan petunjuk teknis Jampersal. Untuk mengatasi minimnya informasi mengenai Jampersal, pemerintah daerah dapat melakukan sosialisasi program.

Dalam menyosialisasikan Jampersal agar dapat diakses maksimal oleh ibu, misalnya pemerintah daerah dapat menggerakkan kader Posyandu dan petugas Puskesmas. Tujuan digulirkannya program itu adalah untuk mendorong percepatan pencapaian satu tujuan Millenium Development Goals (MDG's) tahun 2015 mendatang.

\section{SIMPULAN}

Pelaksanaan Jampersal di Kabupaten Tuban didasari oleh kebijakan Permenkes 613/MENKES/ PER/III/2011, bertujuan mendorong percepatan pencapaian satu tujuan Millenium Development Goals (MDG's) tahun 2015 mendatang. Namun belum maksimal sudah berganti pengelolaannya ke BPJS, sehingga terjadi dilema pengajuan klein dan penganggarannya tersendat-sendat. Kemudian Puskesmas sebagai ujung tombak pelayanan kesehatan sepantasnya memperoleh kecukupan anggaran untuk pelayanan kesehatan masyarakat, utamanya untuk promosi dan prevensi dalam rangka mencapai derajat kesehatan yang optimal, anggaranpun dinilai belum mencukupi.

BOK dimaksudkan untuk mendorong Puskesmas agar mampu mengidentifikasi permasalahan di wilayahnya melalui mini lokakarya yang selanjutnya dapat disusun rencana tindaklanjut untuk pemecahan masalah kesehatan masyarakat miskin, dengan kebijakan operasional BOK utamanya bantuan pemerintah pusat kepada pemerintah daerah, dalam melaksanakan SPM bidang kesehatan, untuk pencapaian MDGs tahun 2015, melalui peningkatan kinerja Puskesmas dan jaringannya serta Poskesdes dan Posyandu dalam pelayanan kesehatan yang bersifat promotif dan preventi, juga belum optimal, sehingga diperlukan koordinasi yang inten antara pemerintah pusat dan pemerintah daerah, saat transisi pengelolaan Jampersal ke BPJS, karena daerah masih menjalankan pola bantuan lama, dianggap proses administrasi BPJS berbeli-belit.

\section{Saran}

Implementasi program Jampersal melalui kebijakan Permekes No. 2562/MENKES/PER/XII/ 2011 terkait pelaksanaan jaminan persalinan pada fasilitas kesehatan tingkat pertama melalui bidan praktik mandiri, belum diimplementasikan dengan baik, dan belum maksimal oleh para bidan praktik mandiri, dikarenakan masih adanya bidan memilih untuk tidak melaksanakan peraturan tersebut dengan konsisten.

Hambatan yang muncul dalam program jaminan persalinan pada fasilitas kesehatan tingkat pertama melalui bidan praktik mandiri adalah. Tidak konsistennya BPM dalam melaksanakan program Jampersal karena mereka menganggap Jampersal memberatkan mereka. Persoalannya pada pembiayaan klaim Jampersal dan aturan administrasi yang harus dipenuhi oleh bidan sebagai syarat pengajuan berkas klaim, diharapkan pola pelayanannya disederhanakan.

Upaya-upaya yang dilakukan untuk mengatasi hambatan yang terjadi dalam pelaksanaan Jampersal melalui BPM adalah dengan mengadakan kesepakatan bersama antara. Dinas Kesehatan dengan semua BPM yang tergabung dalam program Jampersal, dengan memperbolehkan masing-masing BPM untuk menarik biaya tambahan kepada peserta Jampersal sebagai pengganti perlengkapan yang digunakan untuk proses persalinan seperti handuk, dan kelengkapan bayi, hanya sebesar Rp 140.000,00 serta Dinas Kesehatan mengedukasi dan memberikan arahan kepada para BPM terkait pelaksanaan Jampersal ini.

Kedepan pelaksanaan program jaminan kesehatan khusus jaminan persalinan, perlu meningkatkan pengawasan dan pembinaan kepada BPM yang melakukan pelayanan Jampersal, sehingga pelaksanaan Jampersal dapat terlaksana berdasarkan perjanjian kerjasama dan petunjuk teknis Jampersal, diharapkan adanya pertimbangan yang matang atas peralihan pelaksanaan program Jampersal, ke JKN yang dikelola oleh BPJS, karena program Jampersal ini, sudah dirasakan oleh masyarakat dengan gratis, sedang BPJS sistem iuran, maka dikhawatirkan target MDGs untuk menurunkan AKI dan AKB, yang akan berakhir tahun 2015 tidak bisa dicapai, karena waktunya sangat dilematis untuk mencapai target dimaksud.

\section{DAFTAR PUSTAKA}

Dwiyanto, Agus. 2008. Mewujudkan Good Governace Melalui Pelayanan Publik. Gadjah Mada University Press, Yogyakarta.

H. Kurniawan Arianto, SKM 13 Kementerian Kesehatan RI. 2011. Alokasi Anggaran Kesehatan 2011. Jakarta.

Peraturan Perundang-undangan

Undang Undang Nomor 25 Tahun 2009 tentang Pelayanan Publik.

Undang Undang Nomor 36 Tahun 2009 tentang Kesehatan. 
Undang Undang Nomor 40 Tahun 2004 tentang Sistem Jaminan Sosial Nasional.

Referensi Online Website:

Berita Jampersal: www.depkes.go.id. Diakses tanggal 11 November 2011.

Wamenkes saat memberikan paparan pada Seminar Hasil Penelitian Masalah Pelaksanaan Jampersal tahun 2011 dan 2012: www.kesehatanibu.depkes. go.id/archives/462, Diakses 28 Agustus 2012.

Jaminan Persalinan (Jampersal) adalah jaminan pembiayaan:

www.scribd.com/doc/120760873/Riset-EvaluasiJampersal, Diakses 17 Januari 2013.

Jampersal: www.kesehatanibu.depkes.go.id/archives/447, Diakses 10 Agustus 2012.

Kesehatan Ibu dan anak: www.kesehatanibu.depkes. go.id/archives/category/berita-Jampersal. Diakses 28 Agustus 2012.

Pelaksanaan Jampersal: www.rakyatbengkulu.com. Diakses tanggal 3 November 2011

Pelayanan Jampersal: www.kompas.com. Diakses tanggal Diakses 4 November 2011

Pola kesehatan anak: www.belanegara.com. Diakses 11 November 2011

SDM dalam mendukung Jampersal serta utilisasi Jampersal dalam pelayanan kesehatan ibu dan bayi baru lahir: www.scribd.com/doc/120760873/ Riset-Evaluasi-Jampersal. Diakses 17 Januari 2013 